\title{
ANALISIS STABILITAS HASIL GENOTIPE JAGUNG MENGGUNAKAN METODE FIXED AMMI
}

\author{
Modana Lolita $^{1 \S}$, I Komang Gde Sukarsa ${ }^{2}$, Made Susilawati ${ }^{3}$ \\ ${ }^{1}$ Program Studi Matematika, Fakultas MIPA - Universitas Udayana [Email:modanalolita8@gmail.com] \\ ${ }^{2}$ Program Studi Matematika, Fakultas MIPA - Universitas Udayana [Email:sukarsakomang@yahoo.com] \\ ${ }^{3}$ Program Studi Matematika, Fakultas MIPA - Universitas Udayana [Email: mdsusilawati@unud.ac.id] \\ ${ }^{\S}$ Corresponding Author
}

\begin{abstract}
Additive Main Effect and Multiplicative Interaction (AMMI) is a method that is used in research to study interaction between genotype and location. The aim of this research is to apply fixed AMMI in examining the production of corn genotype data and to explore yield stability of its based on biplot picture and AMMI Stability Value (ASV). This research uses six corn genotypes, eight trial locations, and three repetitions. The Interaction Principal Component Analysis (IPCA) that are significant to entered in the model based on analysis of variance fixed $A M M I$ are IPCA $1, I P C A_{2}$, and IPCA $A_{3}$ with total diversity interaction as much as 92,16\%. The biplot picture and ASV should the stable genotype in all location are genotype KUI Carotenoid Syn FS. 17-3-2-B-B $\times$ T01 and genotype CML 305-B-B $\times$ T01. In addition, corns that are able to adapt only in certain location is: genotype KUI Carotenoid Syn FS. 5-1-5-B-B $\times$ T01, genotype KUI Carotenoid Syn FS. 25-3-2-B-B $\times$ T01, genotype KUI Carotenoid Syn FS. 17-3-1-B $\times$ T01, and genotype CML 130-B-B $\times$ T01.
\end{abstract}

Keywords: AMMI, Biplot, Fixed AMMI, Stability

\section{PENDAHULUAN}

Peningkatan produktivitas dan kualitas hasil jagung dapat dilakukan melalui program pemuliaan tanaman. Dalam program pemuliaan tanaman, kestabilan dan daya adaptasi genotipe di berbagai lokasi merupakan salah satu tujuan paling penting untuk meningkatkan produksi tanaman. Respon tanaman yang spesifik terhadap lokasi yang berbeda mengakibatkan adanya interaksi antara genotipe dan lokasi (Gomez \& Gomez, 1995).

Rancangan percobaan merupakan salah satu cara yang digunakan dalam pemuliaan tanaman. Dalam rancangan percobaan, interaksi akan ada apabila genotipe dan lokasi sudah dianggap sebagai faktor. Jika genotipe dan lokasi sudah dianggap sebagai faktor maka rancangan perlakuan yang tepat digunakan adalah rancangan dua faktor sehingga dalam analisis ragam dapat diperhitungkan adanya interaksi. Dalam pendugaan faktor interaksi harus ada pengulangan, baik sebagai pengulangan biasa atau rancangan acak lengkap (RAL) maupun sebagai kelompok atau rancangan acak kelompok (RAK). Apabila ada pengaruh interaksi, uji lanjut yang digunakan dalam analisis ragam adalah uji perbandingan berganda. Namun uji tersebut tidak cukup untuk mendeteksi stabilitas suatu genotipe sehingga diperlukan metode lain untuk melihat stabilitas tersebut. Salah satu metode yang digunakan adalah additive main effect and multiplicative interaction (AMMI).

$A M M I$ merupakan metode yang digunakan peneliti untuk mengamati interaksi antara genotipe dengan lokasi. Interaksi genotipe dengan lokasi (IGL) adalah perubahan keragaman dari dua atau beberapa genotipe pada beberapa lokasi yang berbeda (Mattjik \& Sumertajaya, 2000).

Menurut Mattjik, et al (2011) model AMMI pada dasarnya adalah model dengan faktor tetap (fixed model). Jika diasumsikan genotipe 
dan lokasi ditentukan secara subjektif oleh peneliti dan kesimpulan hanya terbatas pada genotipe dan lokasi yang dicobakan, maka analisis $A M M I$ yang digunakan adalah model AMMI tetap (fixed AMMI). Analisis stabilitas $A M M I$ dapat lihat melalui gambaran biplot $A M M I$ dan indeks stabilitas AMMI (ISA).

Penelitian ini menggunakan data enam genotipe jagung, delapan lokasi percobaan, dan tiga ulangan. Tujuan dari penelitian ini adalah menentukan hasil analisiss data genotipe jagung menggunakan metode fixed AMMI dan menentukan stabilitas enam genotipe jagung berdasarkan gambaran biplot dan ISA.

Model linear percobaan multilokasi dengan fixed AMMI secara lengkap dapat ditulis sebagai berikut:

$$
\begin{aligned}
\gamma_{g e r}= & \mu+\alpha_{g}+\beta_{e}+\sum_{k=1}^{n} \sqrt{\lambda_{k}} \varphi_{g k} \rho_{e k}+ \\
& \vartheta_{g e}+\varepsilon_{g e r}
\end{aligned}
$$

dengan:

$g=1,2, \ldots, a ; e=1,2, \ldots, b ; r=1,2, \ldots, m$.

$\gamma_{g e r}$ menyatakan nilai pengamatan pada genotipe k- $g$, lokasi ke- $e$, dan ulangan ke- $r, \mu$ menyatakan nilai tengah (rataan umum), $\alpha_{g}$ menyatakan pengaruh utama genotipe ke- $g$ terhadap respon yang diamati, $\beta_{e}$ menyatakan pengaruh utama lokasi ke- $e$ terhadap respon yang diamati, $\sqrt{\lambda_{n}}$ menyatakan nilai singular komponen bilinear ke- $n, \varphi_{g n}$ menyatakan pengaruh ganda genotipe ke- $g$ melalui komponen bilinear ke- $n, \rho_{e n}$ menyatakan pengaruh ganda lokasi ke- $e$ melalui komponen bilinear ke- $n$, $\vartheta_{g e}$ menyatakan galat dari pemodelan bilinear, $\varepsilon_{\text {ger }}$ menyatakan pengaruh acak galat faktor tetap genotipe ke- $g$, faktor tetap lokasi ke- $e$, ulangan ke-r, $\left(\varepsilon_{\text {egr }} \stackrel{i i d}{\sim} N\left(0, \sigma_{\varepsilon}{ }^{2}\right)\right)$.

Penentuan banyaknya komponen utama interaksi (KUI) yang dapat masuk ke dalam model dapat ditentukan melalui penguraian nilai singular matriks interaksi $Z$. Penguraian nilai singular untuk matriks $Z$ dapat dimodelkan sebagai berikut:

$$
\mathrm{Z}=\mathrm{USA}^{\mathrm{T}}
$$

matriks $U$ dan $A$ merupakan matriks dengan kolom orthonormal, dan matriks $S$ merupakan matriks diagonal dengan elemen diagonalnya merupakan akar kuadrat nilai eigen positif bukan nol. Unsur-unsur diagonal dari matriks $S$ disebut nilai singular matriks $Z$ (Jolliffe, 2002).

Pada biplot AMMI kontur ellips yang digunakan diperoleh dari perhitungan jari-jari ellips. Apabila suatu genotipe berada didalam kontur maka dapat dikatakan bahwa genotipe tersebut stabil. Sedangkan jika genotipe berada di luar kontur maka genotipe tersebut dapat dikategorikan sebagai genotipe yang tidak stabil atau dapat dikatakan bahwa genotipe stabil pada lokasi tertentu. Persamaan yang digunakan untuk mendapatkan jari-jari elips (Mattjik, et al., 2011) adalah:

$$
r_{i}= \pm \lambda_{i} \sqrt{\left(\frac{2(n-1)}{n(n-p)} F_{p . n-p(\alpha)}\right)}
$$

dengan:

$r_{i}$ menyatakan panjang jari-jari; $i=1$ untuk jari-jari panjang; $i=2$ untuk jari-jari pendek,

$n$ menyatakan banyaknya pengamatan (genotipe + lokasi), $p$ menyatakan banyaknya peubah, $\lambda_{i}$ menyatakan nilai singular, $F_{p . n-p(\alpha)}$ menyatakan nilai sebaran $F$ dengan derajat bebas pertama $\left(\mathrm{db}_{1}\right)$ dan derajat bebas kedua $\left(\mathrm{db}_{2}\right)$ berturut-turut adalah $p$ dan $n-p$, dengan nilai alpha yang digunakan adalah $\alpha=5 \%$.

Untuk mempermudah melihat tingkat stabilitas suatu genotipe terhadap lokasi digunakan indeks stabilitas. Penentuan indeks stabilitas genotipe ditentukan oleh skor $\mathrm{KUI}_{1}$ dan skor $\mathrm{KUI}_{2}$ dari masing-masing genotipe (Mattjik, et al., 2011). ISA didefinisikan sebagai berikut:

ISA $=\sqrt{\left[\frac{\lambda_{1}^{\frac{1}{2}}}{\lambda_{2}{ }^{\frac{1}{2}}}\left(\text { nilai } K U I_{1}\right)\right]^{2}+\left(\text { nilai } K U I_{2}\right)^{2}}$

Indeks dibangun berdasarkan konsep jarak, semakin besar indeks stabilitas suatu genotipe, semakin jauh pula jarak genotipe dari titik pusat sumbu koordinat sehingga genotipe tersebut semakin tidak stabil, begitu pula sebaliknya. 


\section{METODE PENELITIAN}

\section{a. Jenis dan Sumber Data}

Jenis data yang digunakan dalam penelitian ini adalah data sekunder yang diperoleh dari Yasin, et al (2014). Data sekunder yang digunakan berupa data hasil biji genotipe jagung fungsional dengan percobaan enam perlakuan genotipe, delapan lokasi, dan tiga ulangan pada musim hujan tahun 2010. Berikut merupakan tabel kode nama genotipe dan lokasi percobaan:

Tabel 1. Genotipe Jagung

\begin{tabular}{|l|l|}
\hline \multicolumn{1}{|c|}{ Genotipe } & Kode \\
\hline CML 130-B-B $\times$ T01 & G1 \\
\hline KUI Carotenoid Syn FS. 17-3-2-B-B $\times$ T01 & G2 \\
\hline CML 305-B-B $\times$ T01 & G3 \\
\hline KUI Carotenoid Syn FS. 5-1-5-B-B $\times$ T01 & G4 \\
\hline KUI Carotenoid Syn FS. 17-3-1-B $\times$ T01 & G5 \\
\hline KUI Carotenoid Syn FS. 25-3-2-B-B $\times$ T01 & G6 \\
\hline
\end{tabular}

Tabel 2. Lokasi Percobaan

\begin{tabular}{|l|c|}
\hline \multicolumn{1}{|c|}{ Lokasi } & Kode \\
\hline Kebun Percobaan Maros & E1 \\
\hline Kebun Percobaan Bajeng & E2 \\
\hline Kabupaten Polman & E3 \\
\hline Kabupaten Donggala & E4 \\
\hline Kebun Percobaan Pandu & E5 \\
\hline Kebun Percobaan Muneng & E6 \\
\hline Lombok Timur & E7 \\
\hline Kebun Percobaan Sebapo & E8 \\
\hline
\end{tabular}

\section{b. Teknik Analisis Data}

Tahapan analisis dalam penelitian ini adalah: (1) menganalisis data pada analisis ragam percobaan genotipe jagung pada berbagai lokasi dengan analisis ragam dua faktor RAKL. (2) membentuk matriks data berukuran $6 \times 8$. Entri-entri matriks tersebut merupakan data rata-rata dari hasil enam genotipe jagung di delapan lokasi berbeda. (3) menguraikan nilai $S V D$ berdasarkan konsep Analisis Komponen Utama. (4) analisis ragam model fixed AMMI. (5) menghitung kontribusi masing-masing nilai KUI. (6) menghitung indeks stabilitas AMMI. (7) menginter- pretasikan kestabilan genotipe berdasarkan hasil biplot $A M M I_{2}$ dan indeks stabilitas $A M M I$.

\section{HASIL DAN PEMBAHASAN}

\section{a. Analisis Ragam Produksi Jagung}

Pengujian analisis ragam dilakukan untuk melihat apakah ada pengaruh interaksi genotipe dengan lokasi. Berikut merupakan hasil analisis ragam data pengamatan sebelum dilanjutkan dengan analisis $A M M I$.

Tabel 3. Analisis Ragam Produksi Jagung

\begin{tabular}{|c|c|c|c|c|c|}
\hline $\begin{array}{c}\text { Sumber } \\
\text { Keragaman }\end{array}$ & $\mathrm{db}$ & $\mathrm{JK}$ & $\mathrm{KT}$ & $\mathrm{F}_{\text {hitung }}$ & $\mathrm{F}_{\text {tabel }}$ \\
\hline Genotipe & 5 & 123,61 & 24,72 & $44,95^{*}$ & 2,311 \\
\hline Lokasi & 7 & 176,49 & 25,21 & $45,84^{*}$ & 2,109 \\
\hline Interaksi & 35 & 76,19 & 2,17 & $3,96^{*}$ & 1,548 \\
\hline Kelompok & 2 & 0,04 & 0,02 & 0,04 & 3,093 \\
\hline Galat & 94 & 51,72 & 0,55 & & \\
\hline Total & 143 & 428,05 & & & \\
\hline
\end{tabular}

Keterangan: *) Signifikan

Hasil analisis ragam untuk interaksi produksi jagung dari enam genotipe jagung pada delapan lokasi di atas menunjukan bahwa pengaruh utama (genotipe dan lokasi) dan pengaruh interaksi antara genotipe dengan lokasi berpengaruh nyata karena $\mathrm{F}_{\text {hitung }}>\mathrm{F}_{\text {tabel }}$.

\section{b. Penguraian Nilai Singular}

Hasil penguraian nilai singular diperoleh enam nilai singular tak nol, yaitu 3,661032; 2,$502181 ; 1,937493 ; 1,378454 ; 0,3039594$; $2,426457 \times 10^{-15}$. Berdasarkan nilai singular tersebut terlihat bahwa banyaknya KUI yang dapat dipertimbangkan untuk model fixed AMMI adalah komponen pertama sampai keenam. Diperoleh pula enam nilai eigen yaitu $\lambda_{1}=13,40316 ; \quad \lambda_{2}=6,260912 ; \quad \lambda_{3}=$ 3,$753880 ; \lambda_{4}=1,900135 ; \lambda_{5}=0,09239132$; $\lambda_{6}=5,887693 \times 10^{-30}$.

\section{c. Analisis Ragam Data Hasil Produksi Jagung dengan Fixed AMMI}

Dari penguraian nilai singular dengan memperoleh enam nilai eigen, kemudian dilakukan kembali perhitungan analisis ragam model fixed AMMI. Analisis ragam model fixed 
AMMI ini memperlihatkan skor KUI yang signifikan dan dapat masuk ke dalam model

Tabel 4. Analisis Ragam Data Hasil Produksi Jagung dengan Fixed AMMI

\begin{tabular}{|l|r|r|r|r|r|}
\hline $\begin{array}{c}\text { Sumber } \\
\text { Keragaman }\end{array}$ & $\mathrm{db}$ & \multicolumn{1}{c|}{$\mathrm{JK}$} & $\mathrm{KT}$ & $\mathrm{F}_{\text {hitung }}$ & $\mathrm{F}_{\text {tabel }}$ \\
\hline Genotipe & 5 & 123,61 & 24,722 & 44,95 & 2,311 \\
\hline Lokasi & 7 & 176,49 & 25,213 & 45,84 & 2,109 \\
\hline Interaksi & 35 & 76,19 & 2,177 & 3,96 & 1,548 \\
\hline $\mathrm{KUI}_{1}$ & 11 & 40,21 & 3,66 & $6,65^{*}$ & 1,891 \\
\hline $\mathrm{KUI}_{2}$ & 9 & 18,78 & 2,09 & $3,80^{*}$ & 1,981 \\
\hline $\mathrm{KUI}_{3}$ & 7 & 11,26 & 1,61 & $2,93^{*}$ & 2,109 \\
\hline $\mathrm{KUI}_{4}$ & 5 & 5,70 & 0,32 & 0,58 & 2,311 \\
\hline $\mathrm{KUI}_{5}$ & 3 & 0,28 & 0,09 & 0,16 & 2,701 \\
\hline Kelompok & 2 & 0,04 & 0,02 & 0,04 & 3,093 \\
\hline Galat & 94 & 51,725 & 0,55 & & \\
\hline Total & 143 & 428,055 & & & \\
\hline
\end{tabular}

Keterangan: *) Signifikan

Dengan membandingkan nilai $\mathrm{F}_{\text {hitung }}$ dan $\mathrm{F}_{\text {tabel }}$ dapat dilihat pada Tabel 4 bahwa nilai $\mathrm{F}_{\text {hitung }}$ $\mathrm{KUI}_{1}, \mathrm{KUI}_{2}$, dan $\mathrm{KUI}_{3}$ lebih besar dari pada nilai $\mathrm{F}_{\text {tabel. }}$. Dengan demikian keputusan adalah tolak $\mathrm{H}_{0}$. Hal ini berarti $\mathrm{KUI}_{1}, \mathrm{KUI}_{2}$, dan $\mathrm{KUI}_{3}$ berpengaruh terhadap daya hasil produksi jagung, sehingga daya hasil dapat diterangkan dengan menggunakan fixed AMMI model $\mathrm{AMMI}_{3}$.

\section{d. Nilai Kontribusi Komponen Utama Interaksi (KUI)}

Penentuan nilai KUI yang dapat masuk dalam model dapat dilakukan dengan menghitung nilai kontribusi masing-masing KUI. Kontribusi masing-masing KUI adalah $\mathrm{KUI}_{1}$ sebesar 52,75\%; $\mathrm{KUI}_{2}$ sebesar 24,64\%; $\mathrm{KUI}_{3}$ sebesar $14,77 \%$; $\mathrm{KUI}_{4}$ sebesar 7,48\%; $\mathrm{KUI}_{5}$ sebesar $0,36 \%$; dan $\mathrm{KUI}_{6}$ sebesar $0 \%$. Berdasarkan analisis ragam model fixed AMMI dan kontribusi masing-masing KUI dapat dilihat bahwa KUI yang dapat masuk ke dalam model adalah $\mathrm{KUI}_{1}, \mathrm{KUI}_{2}$, dan $\mathrm{KUI}_{3}$. Ketiga komponen utama tersebut mampu memberikan keragaman total produksi tanaman jagung sebesar $52,75 \%+24,64 \%+14,77 \%=92,16 \%$ yaitu suatu tingkat keragaman yang tinggi. Penentuan stabilitas genotipe digunakan skor $\mathrm{KUI}_{1}$ dan skor $\mathrm{KUI}_{2}$, sehingga dari dua KUI yang digunakan kontribusi keragaman yang diberikan sudah cukup tinggi yaitu sebesar 52,75\% $+24,64 \%=$ 77,39\%. Menurut Trisnayanti, et al (2015), hal ini sudah melebihi dari $50 \%$ atau sudah cukup untuk dapat menentukan stabilitas genotipe.

\section{e. Daerah Kepercayaan Biplot}

Biplot $A M M I_{2}$ dari analisis $A M M I$ dapat digunakan untuk melihat genotipe-genotipe yang stabil pada seluruh lokasi percobaan. Dalam membantu melihat genotipe-genotipe yang stabil digunakan daerah kepercayaan elips pada biplot dengan titik pusat $(0,0)$. Penentuan stabilitas genotipe digunakan dua nilai KUI dengan keragaman terbesar pertama dan kedua, hal ini dikarenakan gambaran biplot hanya terbatas pada dua dimensi. Kontribusi keragaman yang diberikan dari dua nilai KUI yang digunakan cukup tinggi yaitu sebesar 77,39\%. Menurut Trisnayanti, et al (2015), hal ini sudah melebihi $50 \%$ atau sudah lebih dari cukup untuk dapat menentukan stabilitas genotipe.

Hasil plot Gambar 1 menggambarkan keragaman interaksi sebesar 77,39\% dengan masing-masing nilai $\mathrm{KUI}_{1}$ sebesar $52,75 \%$ dan $\mathrm{KUI}_{2}$ sebesar $24,64 \%$. Kontur yang terbentuk sebagai daerah keper-cayaan berbentuk elips.

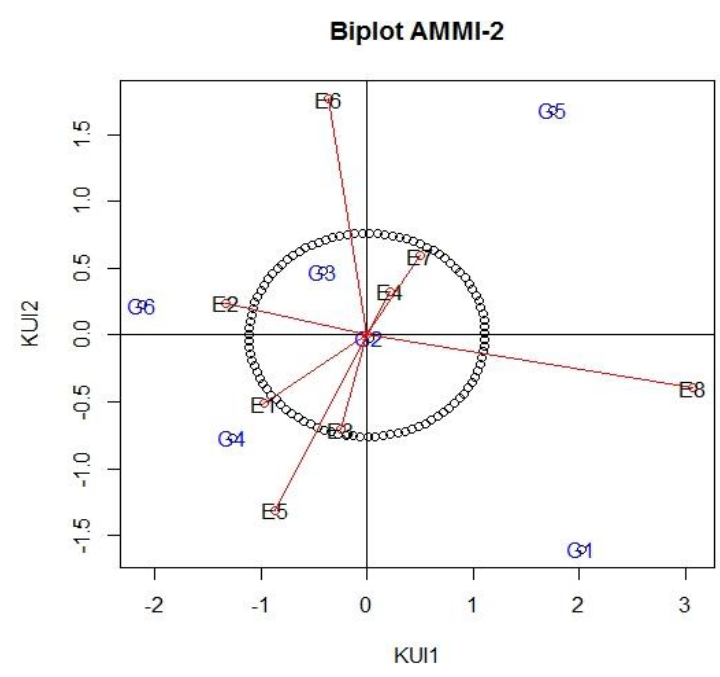

Gambar 1. Bipot $\mathrm{AMMI}_{2}$

Konsep kestabilan juga ditunjukan dari ISA yang melihat posisi relative genotipe terhadap 
titik pusat biplot $A M M I_{2}$. Hasil perhitungan ISA dapat dilihat pada Tabel 5. Hasil ISA untuk masing-masing genotipe kemudian diurutkan berdasarkan peringkat dari genotipe dengan indeks terkecil hingga genotipe dengan indeks terbesar.

Berdasarkan gambar biplot $A M M I_{2}$ dan ISA dapat diduga bahwa genotipe yang stabil untuk seluruh lokasi percobaan adalah genotipe yang berada di dalam area kontur dan memiliki jarak yang dekat dengan titik pusat $(0,0)$. Genotipegenotipe yang dikategorikan stabil pada seluruh lokasi percobaan bila berdasarkan biplot $A M M I_{2}$ dan ISA adalah $\mathrm{G}_{2}$ dengan jarak

Tabel 5. Indeks Stabilitas AMMI (ISA)

\begin{tabular}{|c|c|c|}
\hline Genotipe & ISA & Peringkat \\
\hline G1 & 1,63 & 6 \\
\hline G2 & 0,02 & $1^{*}$ \\
\hline G3 & 0,40 & 2 \\
\hline G4 & 0,93 & 3 \\
\hline G5 & 1,53 & 5 \\
\hline G6 & 1,34 & 4 \\
\hline
\end{tabular}

Keterangan :*) genotipe paling stabil

sebesar 0,02 yang berada pada peringkat pertama dan $\mathrm{G}_{3}$ dengan jarak 0,04 . Sedangkan untuk genotipe yang tidak stabil atau genotipe yang hanya mampu beradaptasi pada suatu lingkungan tertentu adalah genotipe yang berada di luar area kontur dan memiliki jarak yang jauh dengan titik pusat $(0,0)$. Genotipegenotipe yang dikategorikan sebagai genotipe yang hanya mampu beradaptasi pada suatu lingkungan tertentu adalah $\mathrm{G}_{4}, \mathrm{G}_{6}, \mathrm{G}_{5}$, dan $\mathrm{G}_{1}$ dengan masing-masing memiliki jarak terhadap titik pusat $(0,0)$ sebesar 0,$93 ; 1,34 ; 1,53 ; 1,63$. Genotipe-genotipe yang hanya mampu beradaptasi pada suatu lokasi tertentu dapat dilihat berdasarkan korelasi antar peubah. Jika sudut di antara dua vektor peubah kecil, maka korelasi di antara dua peubah tersebut cenderung besar. Genotipe-genotipe yang mampu beradaptasi pada lokasi tertentu dapat dilihat pada Tabel 6.
Tabel 6. Klasifikasi Genotipe

\begin{tabular}{|c|l|}
\hline Genotipe & \multicolumn{1}{|c|}{ Lokasi } \\
\hline $\mathrm{G}_{4}$ & $\begin{array}{l}\text { Kebun Percobaan Maros, Kabupaten } \\
\text { Polman, dan Kebun Percobaan } \\
\text { Pandu }\end{array}$ \\
\hline $\mathrm{G}_{6}$ & $\begin{array}{l}\text { Kebun Percobaan Bajeng dan Kebun } \\
\text { Percobaan Muneng }\end{array}$ \\
\hline $\mathrm{G}_{5}$ & $\begin{array}{l}\text { Kabupaten Donggala dan Lombok } \\
\text { Timur }\end{array}$ \\
\hline $\mathrm{G}_{1}$ & Kebun Percobaan Sebapo \\
\hline
\end{tabular}

\section{KESIMPULAN DAN SARAN}

Berdasarkan pembahasan tersebut, dapat disimpulkan bahwa model fixed AMMI pada pada data hasil enam genotipe jagung di delapan lokasi dan tiga ulangan diperoleh tiga komponen utama interaksi yang signifikan dengan total keragaman $92,16 \%$.

Penentuan kestabilan genotipe dengan menggunakan biplot $A M M I_{2}$ dengan keragaman interaksi sebesar $77,39 \%$ dan ISA diperoleh genotipe-genotipe yang dikategorikan mampu memberikan hasil yang baik pada seluruh lokasi percobaan adalah KUI Carotenoid Syn FS. 17-3-2-B-B x T01 dan CML 305-B-B x T01. Sedangkan KUI Carotenoid Syn FS. 5-15-B-B x T01 mampu memberikan hasil yang baik apabila ditanam di Kebun Percobaan Maros, Kabupaten Polman, dan Kebun Percobaan Pandu. KUI Carotenoid Syn FS. 253-2-B-B x T01 mampu memberikan hasil yang baik apabila ditanam di Kebun Percobaan Bajeng dan Kebun Percobaan Muneng. KUI Carotenoid Syn FS. 17-3-1-B x T01 mampu memberikan hasil yang baik apabila ditanam di Kabupaten Donggala dan Lombok Timur. CML 130-B-B x T01 mampu memberikan hasil yang baik apabila ditanam di Kebun Percobaan Sebapo.

Sebagai saran bagi pembaca yang tertarik dengan topik ini dapat membahas mengenai Mixed AMMI, Generalized Linear Model AMMI (GLM-AMMI), dan Expectation Maximitation AMMI (EM-AMMI). 


\section{DAFTAR PUSTAKA}

Gomez, K. A \& Gomez, A. A. (1995). Prosedur Statistik untuk Penelitian Pertanian. (Edisi ke-2).Terjemahan oleh Sjamsudin dan Baharsjah. Jakarta: UIPress.

Jolliffe, I. (2002). Principal Component Analysis. (Second Edition). New York: Springer.

Mattjik, A. A., \& Sumertajaya, I. M. (2000). Perancangan Percobaan dengan Aplikasi SAS dan Minitab. Bogor: IPB Press.

Mattjik, A. A., Sumertajaya, I. M., Hadi, A. F., \& Wibawa, G. N. A. (2011). Pemodelan Additive Main-Effect and Multiplicative Interaction (AMMI): Kini dan yang Akan Datang. Bogor: IPB Press.

Trisnayanti, N. P. A. D., Suciptawati, N. P., \& Sukarsa, I.G. (2015). Implementasi Metode Bootstrap dalam Inferensi Titik-Titik Biplot AMMI Model AMMI Campuran (Mixed AMMI). Jurnal Matematika, 4, 115-121.

Yasin HG, M., Sumarno., \& Nur. A. (2014). Perakitan Varietas Unggul Jagung Fungsional. Bogor: Badan Penelitian dan Pengembangan Pertanian. 